\title{
Densidade de drenagem da bacia incremental do reservatório de Porto Primavera, rio Paraná (SP/MS): perspectiva de sua adoção como indicador de produção de sedimentos das bacias hidrográficas.
} \author{
Aloisio Celer ${ }^{7}$

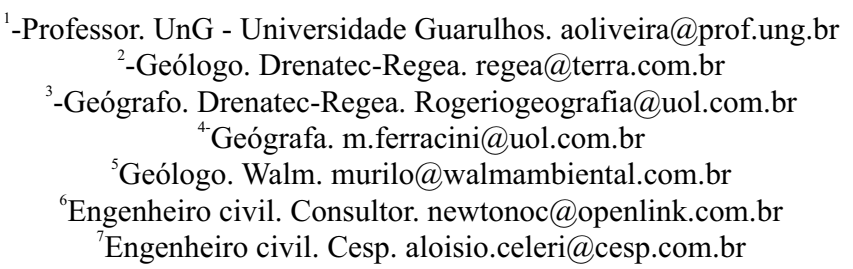

Antônio Manoel dos Santos ${ }^{1}$, Carlos Frederico de Castro Alves. ${ }^{2}$, Rogério Gutierrez Gama $^{3}$, Mirna Mangini Ferracini ${ }^{4}$, Murilo César Vieira Perrella ${ }^{5}$, Newton Oliveira Carvalho ${ }^{6}$,

\begin{abstract}
Resumo
Este trabalho apresenta os resultados de pesquisa sobre a densidade de drenagem da bacia hidrográfica incremental do reservatório de Porto Primavera, rio Paraná (SP/MS). As conclusões obtidas destacam aos métodos adotados e à caracterização da bacia, sob a ótica da produção de sedimentos. Os métodos contemplaram a medida dos comprimentos das linhas de drenagem por área considerada $\left(\mathrm{km} / \mathrm{km}^{2}\right)$ e a contagem do número de confluências $\left(\mathrm{nc} / \mathrm{km}^{2}\right)$ em cartas topográficas de diferentes escalas. A caracterização da bacia evidenciou as áreas e as sub-bacias com maior tendência potencial de produção de sedimentos segundo o fator densidade de drenagem.
\end{abstract}

Palavras chave: Densidade de drenagem, bacia hidrográfica, reservatório, produção de sedimentos

\begin{abstract}
This paper presents the results of a research about drainage density applied to the hydrographic basin of Porto Primavera, Parana River (São Paulo / Mato Grosso do Sul Brazil). The conclusions deal with the methods adopted and the characterization of the basin by the sediment production viewpoint. The methods encompassed the length measurement of drainage lines in determined areas $\left(\mathrm{km} / \mathrm{km}^{2}\right)$ and number of confluences counting $\left(\mathrm{nc} / \mathrm{km}^{2}\right)$ in topographic charts at several scales. The characterization of the basin has revealed the areas and sub-basins with greater potential to sediment production, according to drainage density.
\end{abstract}

Keywords: Drainage density, hydrographic basin, reservoir, sediment production

\section{Introdução}

Durante dois anos, de 2001 a 2003, foram realizados estudos sobre o assoreamento do reservatório de Porto Primavera, da Usina Hidroelétrica Eng. Sérgio Motta, implantada no rio Paraná (MS/SP), compreendendo diagnóstico e determinação de medidas preventivas do processo de assoreamento desse reservatório (Walm, 2003).

Tais estudos, que estavam previstos nos programas estabelecidos no Estudo de Impacto Ambiental e Relatório de Impacto ao Meio Ambiente EIA/Rima do empreendimento (Cesp- Companhia Energética de São Paulo), envolveram medições hidrossedimentométricas e a caracterização do potencial de produção de sedimentos da bacia incremental, ou seja, da bacia contribuinte delimitada a jusante do reservatório de Jupiá, ocupando uma área total de $92.761 \mathrm{~km}^{2}$. 
Dentre os fatores adotados para a caracterização dessa bacia, foi usado o fator morfométrico densidade de drenagem cuja aplicação motivou o desenvolvimento da pesquisa ora apresentada neste trabalho.

No presente trabalho, a densidade de drenagem foi adotada para ponderar, como um dos fatores, o potencial de transferência de sedimentos das sub-bacias diretamente contribuintes do reservatório de Porto Primavera.

Embora qualitativa, essa análise visa classificar as sub-bacias quanto ao processo de produção de sedimentos, bem como verificar a distribuição espacial da densidade de drenagem em cada sub-bacia, favorecendo a interpretação de medidas hidrossedimentométricas.

Este trabalho tem por objetivo apresentar e discutir os resultados obtidos, tanto no que se refere à caracterização das sub-bacias da bacia incremental de Porto Primavera, quanto à avaliação dos procedimentos adotados.

\section{2- Densidade de drenagem: importante fator morfométrico das bacias hidrográficas}

O conceito de densidade de drenagem é relativamente antigo, tendo sido formulado pela primeira vez, segundo Christofoletti (1983), por Neuman (1900) através da relação entre a soma do comprimento $(\mathrm{km})$ de todos os cursos d'água em determinada área e a sua superfície $\left(\mathrm{km}^{2}\right)$. Ainda segundo aquele autor, foi Horton (1945) que definiu essa área como sendo a área delimitada como uma bacia hidrográfica.

Desde então, esse parâmetro morfométrico das bacias hidrográficas vem sendo estudado e aplicado para a interpretação de vários aspectos do meio físico.

Os estudos sobre o parâmetro referemse basicamente aos procedimentos adotados para a sua medição e suas relações com outros parâmetros morfométricos. Os procedimentos de medida vêm evoluindo em função do desenvolvimento tecnológico, especialmente na área de informática, que propicia os mapeamentos automáticos, a partir de sensoriamento remoto, e medidas automáticas de comprimentos de linhas como, por exemplo, softwares, como o AutoCAD (Autodesk, 2004). Christofoletti (1979) apresenta uma ampla análise dos diversos procedimentos adotados, destacando: medidas de comprimentos de linhas de drenagem; contagem de número de confluências; contagem do número de intersecções de linhas de drenagem com retículos estabelecidos, etc. A adoção de um ou outro procedimento depende sobretudo do tamanho da bacia, da escala de abordagem e dos materiais disponíveis. Assim, por exemplo, o procedimento da contagem do número de confluências tem a vantagem de ser um processo manual rápido, e pode ser realizado por pequenas unidades de áreas (por exemplo, quadrículas com alguns quilômetros quadrados em cartas topográficas de grande escala) para depois os resultados serem plotados em cartas com escalas menores (Almeida \& Romariz, 1988).

Quanto às aplicações, esse parâmetro tem sido usado, por um lado, por constituir resultado de inter-relações de fatores condicionantes do meio físico, como clima, especialmente pluviometria, substrato geológico, relevo, solos, etc., permitindo, portanto, que sejam correlacionados entre si (Demattê, 1992; Silva, 1993). Por outro lado, porque decorre da drenagem, e de sua densidade, o maior ou menor escoamento d'água de uma bacia e, assim também, o transporte de sedimentos (Abrahams, 1972 in Christofoletti, 1979; Chakraborti, 1991; CalvoAlvarado \& Gregory, 1997). Finalmente, destacam-se estudos que envolvem alterações da densidade de drenagem ao longo do tempo, sejam devidas a causas naturais, como em Christofoletti (1983), que apresenta sua significância paleoclimática; sejam a causas antrópicas, como em Rodrigues (2003).

Conclui-se que a densidade de drenagem, dada a simplicidade de sua definição e mensuração, constitui um dos principais parâmetros morfométricos que vêm sendo usados desde muito tempo até hoje, em diversas aplicações para o conhecimento do comportamento do meio físico. Não obstante, há diversos problemas que precisam ser considerados quanto aos procedimentos de mensuração, sobretudo as diferentes escalas dos mapas topográficos disponíveis e as diferentes técnicas adotadas para o mapeamento das linhas de drenagem.

No que se refere especificamente à produção de sedimentos das bacias hidrográficas, pode-se considerar que a rede de drenagem executa uma das etapas desse processo. Com efeito, o processo de produção de sedimentos de uma bacia pode ser considerado em duas etapas: a de erosão propriamente dita, ou seja, aquela em que as partículas deixam de ser integrantes da estrutura de um solo e passam a constituir sedimentos liberados para serem transportados e a de transferência desses sedimentos para o exutório da bacia, que pode corresponder a um reservatório ou a um curso d'água de maior porte. Diversos fatores controlam cada uma dessas etapas, sendo conhecidos os fatores contemplados pela USLE (Universal Soil Loss Equation) para a erosão (Bertoni e Lombardi, 1985). Para a transferência de sedimentos, além desses fatores, são considerados aqueles relacionados à Hidrologia, referentes à modelagem de escoamentos superficiais como a MUSLE (Modified USLE) de Williams (1975). Ao lado da modelagem analítica, com procedimentos cada vez mais complexos, como o modelo WEPP (Water Erosion Prediction 
o modelo WEPP (Water Erosion Prediction Project) (Foster, 1987), desenvolvem-se modelos empíricos que consideram fatores do meio físico condicionantes da transferência, como, por exemplo, Chakraborti (1991); Calvo-Alvarado \& Gregory (1997). Nesses dois exemplos, a densidade de drenagem é um dos parâmetros adotados para a previsão da produção de sedimentos. Com efeito, a densidade de drenagem possui uma relação direta com o potencial de transferência de sedimentos, uma vez que, quanto maior a densidade de drenagem, menor é a distância percorrida pela partícula, deslocada por erosão, do terreno na vertente até o curso d'água.

\section{Características principais da bacia}

A área de estudo contempla a bacia hidrográfica incremental ao reservatório de Porto Primavera da Usina Hidroelétrica Sérgio Motta, ou seja, todas as bacias hidrográficas afluentes ao rio Paraná cujos exutórios se encontram entre as barragens de Porto Primavera e Jupiá (Fig. 1).

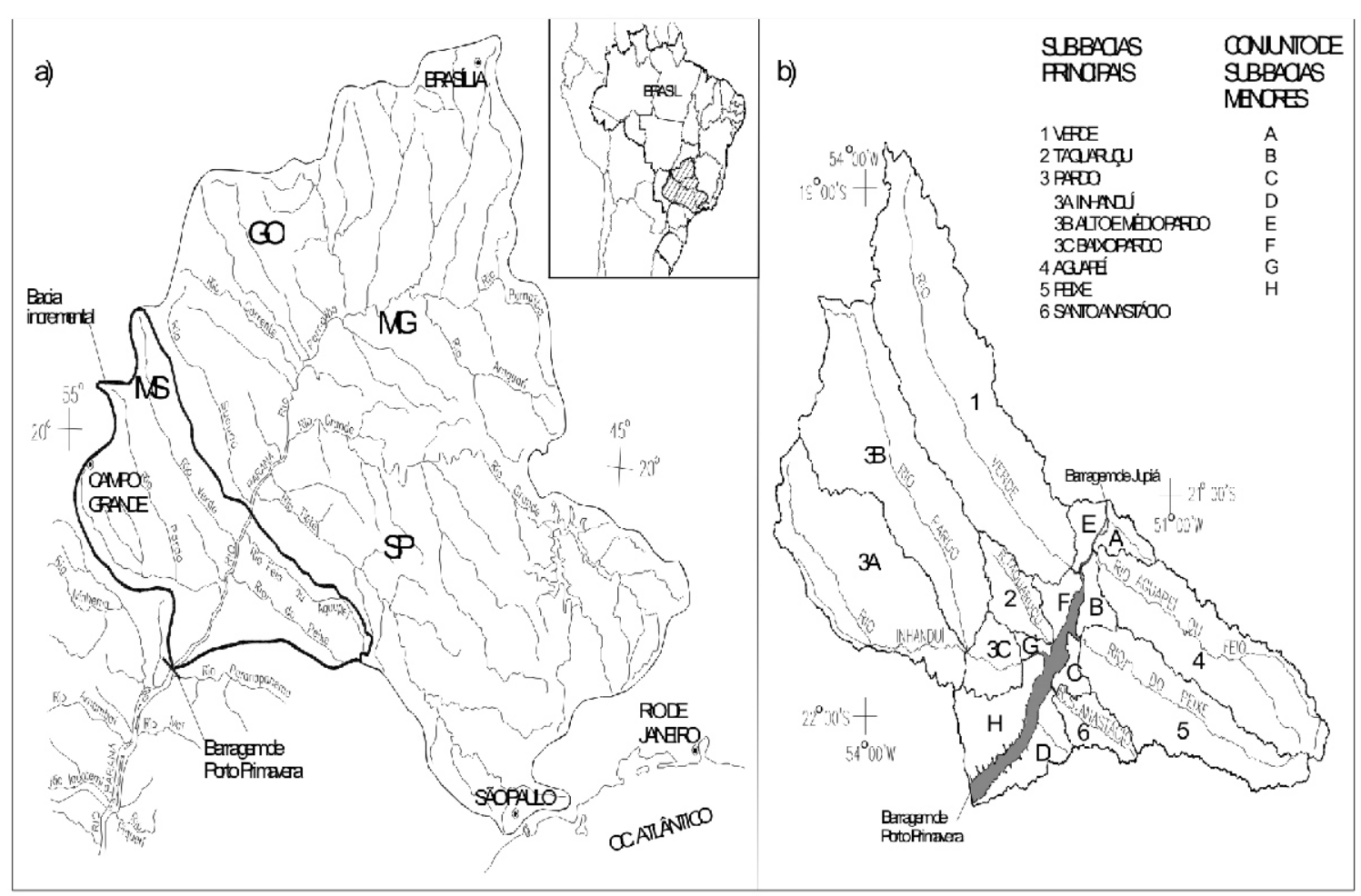

Figura 1. Localização da área de estudo. a) Bacia incremental do reservatório de Porto Primavera na bacia do rio Paraná. b) Sub-bacias da bacia incremental do reservatório de Porto Primavera.2.

A bacia incremental, com $92.761 \mathrm{~km}^{2}$, apresenta assimetria marcada pelas diferentes áreas da margem esquerda, no estado de São Paulo (SP) e direita, no estado de Mato Grosso do Sul (MS) com, respectivamente, $29.214 \mathrm{~km}^{2}$ $(31 \%)$ e $63.547 \mathrm{~km}^{2}(69 \%)$ da área total.

A pluviosidade média anual encontra-se entre 1250 e $1600 \mathrm{~mm}$, sendo os maiores valores encontrados nas cabeceiras tanto no lado SP como MS. A chuvas máximas em 24 horas ocorrem com maior intensidade nos espigões, e concentram-se no período chuvoso, de outubro a março (Themag/Engea/Umah, 1994).

O substrato rochoso predominante corresponde às rochas sedimentares do Grupo Bauru $(89 \%$ da área total) favorecendo o desenvolvimento de solos arenosos. Na margem esquerda (SP) são encontradas rochas menos permeáveis (lamitos, siltitos e camadas com da cimentação carbonática). Secundariamente, são encontrados basaltos da Formação Serra Geral sobretudo na margem direita (MS), relacionados principalmente a fundos de vales, onde se desenvolvem solos argilosos. Depósitos aluvionares, predominantemente arenosos, acompanham os cursos d'água de maior porte (IPT, 1981a; Seplan/MS \& IBGE DRN/GO, 1987).

Quanto ao relevo, 97\% do lado MS é colinoso (com amplo predomínio das rampas e colinas amplas). O restante é constituído por planícies e terraços fluviais (Seplan/MS \& IBGE DRN/GO, 1987). No lado de SP o relevo é mais movimentado, condicionado possivelmente, pela presença de rochas menos permeáveis, sendo marcantes as ocorrências de morrotes na região entre Pirapozinho e Flórida Paulista e escarpas na região do Planalto de Marília, nas 
cabeceiras das sub-bacias do Aguapeí e Peixe (IPT, 1981b).

A bacia incremental foi compartimentada em sub-bacias de grande porte, apresentadas na Figura 1. Todas foram delimitadas considerando o exutório no lago de Porto Primavera, na cota de 257 $\mathrm{m}$, até uma área mínima de $2.073 \mathrm{~km}^{2}$, correspondente à sub-bacia do rio Santo Anastácio. As de área inferior foram agrupadas em conjuntos de sub-bacias de porte menor. Este trabalho focaliza especificamente as sub-bacias maiores, cujas áreas são apresentadas na Tabela 1.

A maior sub-bacia é a do Pardo, que totaliza, somando-se suas três sub-bacias, perto

Tabela 1. Áreas das sub-bacias da bacia incremental do reservatório de Porto Primavera

\begin{tabular}{|c|c|c|}
\hline \multicolumn{2}{|r|}{ Sub-bacia } & Área $\left(\mathrm{km}^{2}\right)$ \\
\hline \multirow{5}{*}{ MS } & Verde & 22.325 \\
\hline & Taquaruçu & 2.575 \\
\hline & Inhanduí & 13.709 \\
\hline & Alto e Médio Pardo & 16.935 \\
\hline & Baixo Pardo & 2.245 \\
\hline \multirow{3}{*}{ SP } & Aguapeí & 12.055 \\
\hline & Peixe & 9.979 \\
\hline & Santo Anastácio & 2.073 \\
\hline
\end{tabular}

de $33.000 \mathrm{~km}^{2}$ (cerca de $33 \%$ da área total). Seguese a ela a sub-bacia do Verde com cerca de $24 \%$ da área total. As sub-bacias do Aguapeí e Peixe (terceira e quarta maiores) possuem respectivamente $13 \%$ e $11 \%$ da área total. Essas quatro sub-bacias perfazem um total de, aproximadamente, $81 \%$ da área da bacia incremental.

Não foram observadas grandes variações na pluviosidade média anual entre as sub-bacias; nem quanto à geologia, se for considerada a ocorrência predominante dos arenitos Bauru. As maiores diferenças destacam-se quanto ao relevo. No lado SP, que apresenta os relevos mais movimentados, destaca-se a sub-bacia do Peixe, com $31 \%$ da área ocupada por morrotes e escarpas. Em seguida, a do Aguapeí, com 12\% da área com morrotes e $53 \%$ com colinas médias e a do Santo Anastácio $(52 \%$ de colinas médias e $5 \%$ de morrotes). No lado de MS, de relevo menos acidentado, destaca-se a sub-bacia do Taquaruçu, com $20 \%$ da área, ocupada por colinas médias. A sub-bacia com relevo mais plano é a do Inhanduí com $93 \%$ da área ocupadas por colinas amplas.

\section{Materiais e métodos}

Para a realização da análise da densidade de drenagem da bacia incremental de Porto Primavera, foram aplicados procedimentos e níveis de abordagem diferentes, conforme as escalas das cartas topográficas adotadas e os propósitos da pesquisa.

Numa primeira etapa, foi determinado o índice de densidade de drenagem, em $\mathrm{km} / \mathrm{km}^{2}$, de cada sub-bacia, em cartas 1:250.000, disponíveis tanto para o lado de MS, quanto para o de SP. A medida do total de comprimentos de drenagens de cada sub-bacia foi obtida através do software AutoCAD Map200i (Autodesk, 2004) em bases digitalizadas. Essa medida foi dividida pela área da respectiva sub-bacia obtendo-se o valor em $\mathrm{km} / \mathrm{km} 2$. Foram utilizadas 14 cartas 1:250.000, 11 editadas pelo IBGE Instituto Brasileiro de Geografia e Estatística (1976 a 1985) e 3 pela Diretoria de Serviço Geográfico do Ministério do Exército, (DSG, 1982 a 1999), conforme articulação apresentada na Figura 2.

Numa segunda etapa, procurou-se realizar um mapeamento da distribuição da densidade de drenagem na área de cada sub-bacia, utilizando-se as cartas de escalas maiores disponíveis, ou seja, 1:50.000 para o lado de SP e 1:100.000 para o lado de MS.

Conforme articulação apresentada na Figura 3, para o Estado de São Paulo foram utilizadas 64 cartas 1:50.000, sendo 50 editadas pelo IBGE (1973 a 1975) e 14 pelo IGG/SP Instituto Geográfico e Geológico do Estado de São Paulo (1967). Para o Estado do Mato Grosso do Sul, pode ser vista, na mesma Figura 3, a articulação das 35 cartas 1:100.000 utilizadas, sendo 28 editadas pela DSG (1971 a 1974) e 7 pelo IBGE (1976 a 1978).

A realização desse mapeamento implicou a adoção de unidades espaciais, relativamente pequenas em relação ao porte das sub-bacias, para se poder obter uma distribuição espacial adequada dos índices de densidade de drenagem em cada sub-bacia. Foram assim adotadas as menores quadrículas desenhadas nas cartas, ou seja, quadrículas de 2 × $2 \mathrm{~km}\left(4 \mathrm{~km}^{2}\right)$ nas 


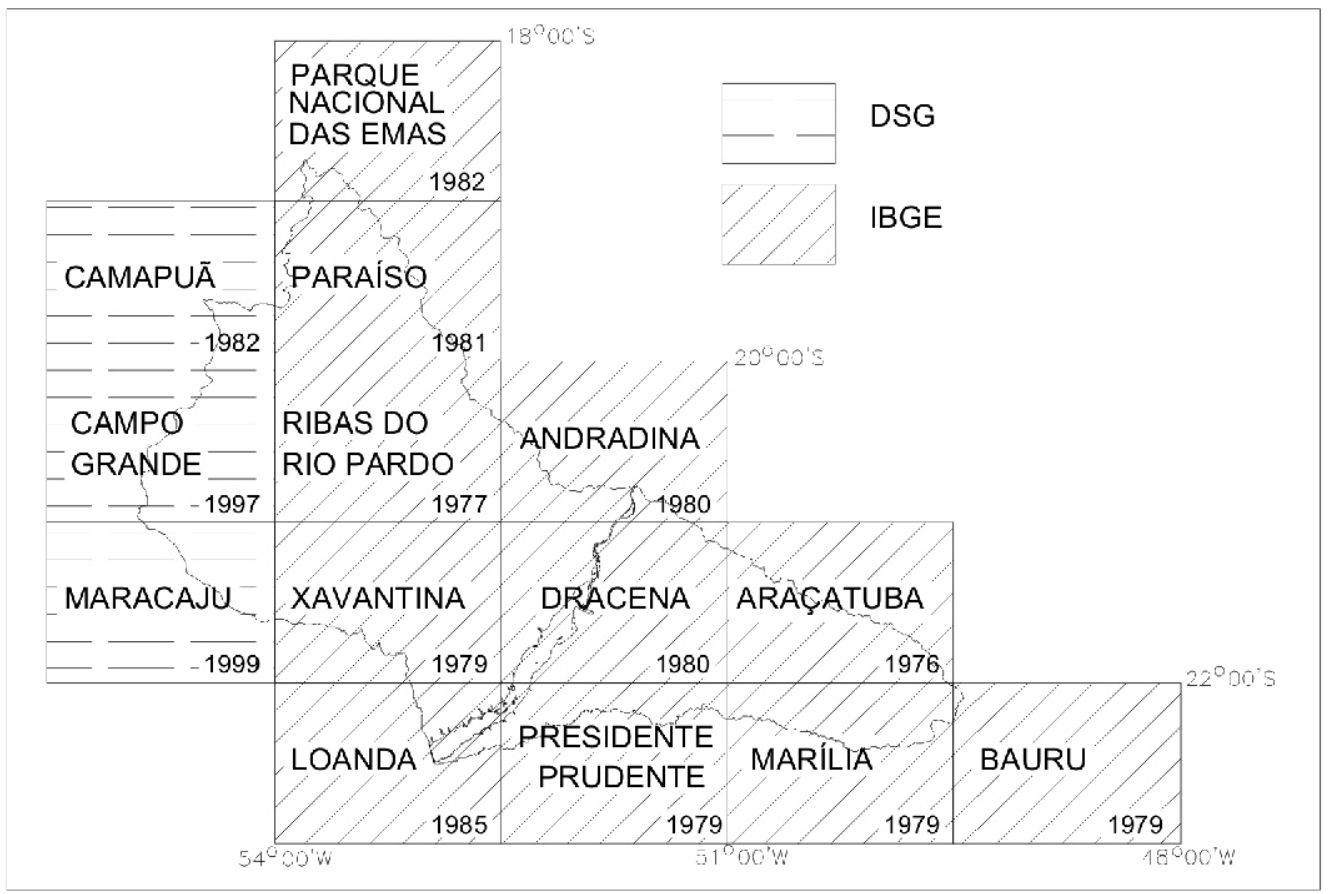

Figura 2- Articulação das cartas topográficas 1:250.000

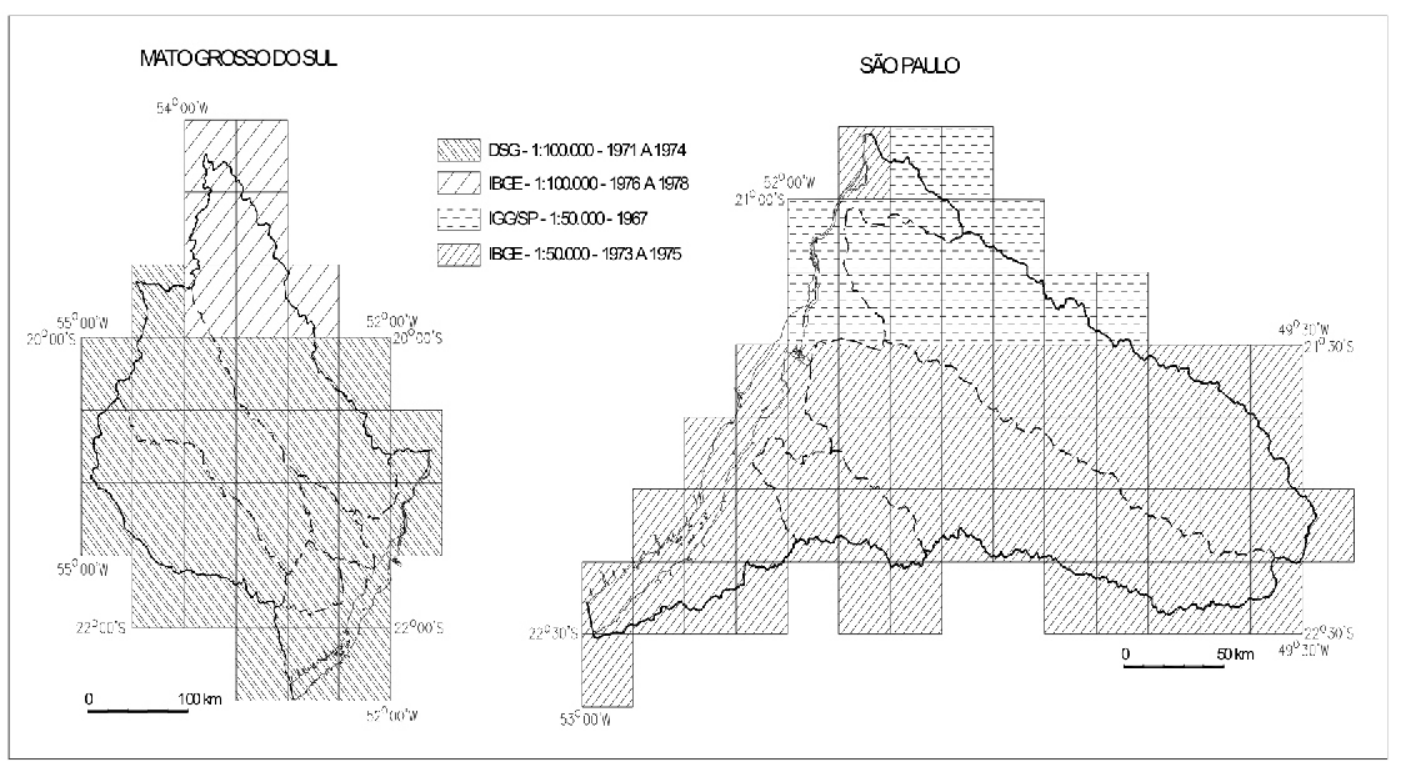

Figura 3. Articulação das cartas topográficas 1:100.000(MS) e 1:50.000(SP)

cartas 1:50.000 (SP) e quadrículas de 4 x 4 km (16 $\mathrm{km}^{2}$ ) nas cartas 1:100.000 (MS). Entretanto, não se dispondo de bases digitalizadas e considerando-se o grande número de cartas a serem pesquisadas, o procedimento aplicado, objetivando a otimização do tempo de trabalho, foi o de contagem do número de confluências de drenagem em cada quadrícula $\left(\mathrm{nc} / \mathrm{km}^{2}\right)$.

Esse procedimento $\left(\mathrm{nc} / \mathrm{km}^{2}\right)$ vem sendo utilizado por vários pesquisadores (Christofoletti, 1979; 1983), e ensaios de correlação com o índice $\mathrm{km} / \mathrm{km}^{2}$ foram considerados satisfatórios (Almeida \& Romariz, 1988). Para a bacia incremental, procurou-se 
também estabelecer o grau de correlação entre os procedimentos. Para isso foi escolhida a sub-bacia do rio Santo Anastácio, a menor sub-bacia da área, determinando-se, além do número de confluências por contagem, o comprimento da drenagem por curvímetro manual, em cada uma das 557 quadrículas de $4 \mathrm{~km}^{2}$.

Para toda a bacia incremental foi elaborada uma tabela contendo as coordenadas UTM do centro da quadrícula e os respectivos números de confluências de drenagem obtidos pela contagem. Através desses dados foi elaborado, utilizando-se o software Surfer 8 (Golden Software Inc., 2002), um mapa de pontos de confluência de drenagem.

Com o objetivo de se determinar os intervalos representativos de diferentes classes de densidade de drenagem (alta, média, baixa) foi realizado um ensaio de correlação entre os tipos de relevo mapeados pelo IPT (1981b) na sub-bacia do Peixe, considerada como representativa da bacia incremental, por apresentar os diferentes tipos de relevo da bacia, desde as planícies aluviais até as escarpas, e pelo fato de toda sua cartografia ter sido realizada em um mesmo projeto do IBGE.

Os intervalos determinados para a subbacia do Peixe foram aplicados para toda a bacia incremental. Para cada classe foi atribuído um tom de cinza de tal forma que o resultado final apresentou as áreas com as diversas classes de densidade de drenagem.

\subsection{Densidade de drenagem $\mathrm{km} / \mathrm{km}^{2}$ das sub- bacias da bacia incremental de Porto Primavera}

Os resultados obtidos a partir das cartas 1:250.000, apresentados na Tabela 2, mostram que as densidades de drenagem das sub-bacias do lado SP apresentam índices de densidade de drenagem muito superiores aos das sub-bacias do lado MS, quase o dobro dos valores. No lado SP destaca-se a sub-bacia do Santo Anastácio com o maior índice.

\subsection{Correlação entre procedimentos para}

Tabela 2. Densidades de drenagem das sub-bacias da bacia incremental de Porto Primavera

\begin{tabular}{|c|c|c|c|c|}
\hline \multicolumn{2}{|c|}{ Sub-bacia } & $\begin{array}{l}\text { Área } \\
\left(\mathrm{km}^{2}\right)\end{array}$ & $\begin{array}{c}\text { Comprimento } \\
\text { das drenagens } \\
(\mathrm{km})\end{array}$ & $\begin{array}{c}\text { Densidade de } \\
\text { drenagem } \\
\left(\mathrm{km} / \mathrm{km}^{2}\right)\end{array}$ \\
\hline \multirow{5}{*}{ MS } & Verde & 22.325 & 5.102 & 0,229 \\
\hline & Taquaruçu & 2.575 & 627 & 0,243 \\
\hline & Pardo Alto e Médio Pardo & 16.935 & 4.183 & 0,247 \\
\hline & $\left(32.889 \mathrm{~km}^{2}\right)$ Inhanduí & 13.709 & 3.458 & 0,252 \\
\hline & Baixo Pardo & 2.245 & 593 & 0,264 \\
\hline \multirow{3}{*}{ SP } & Aguapeí & 12.055 & 5.194 & 0,431 \\
\hline & Peixe & 9.979 & 4.340 & 0,435 \\
\hline & Santo Anastácio & 2.073 & 1.050 & 0,507 \\
\hline
\end{tabular}

determinação de índices de densidade de drenagem $\mathrm{km} / \mathrm{km}^{2}$ e $\mathrm{nc} / \mathrm{km}^{2}$

O resultado desta correlação, apresentado na Figura 4, atingiu um coeficiente de $\mathrm{km} / \mathrm{km}^{2}$. determinação de 79 \%, na correlação polinomial, à semelhança do que foi pesquisado por Almeida \& Romariz (1988), confirmando a viabilidade de aplicação do método para a área de estudo e fornecendo a equação de correlação entre $\mathrm{nc} / \mathrm{km}^{2} \mathrm{e}$

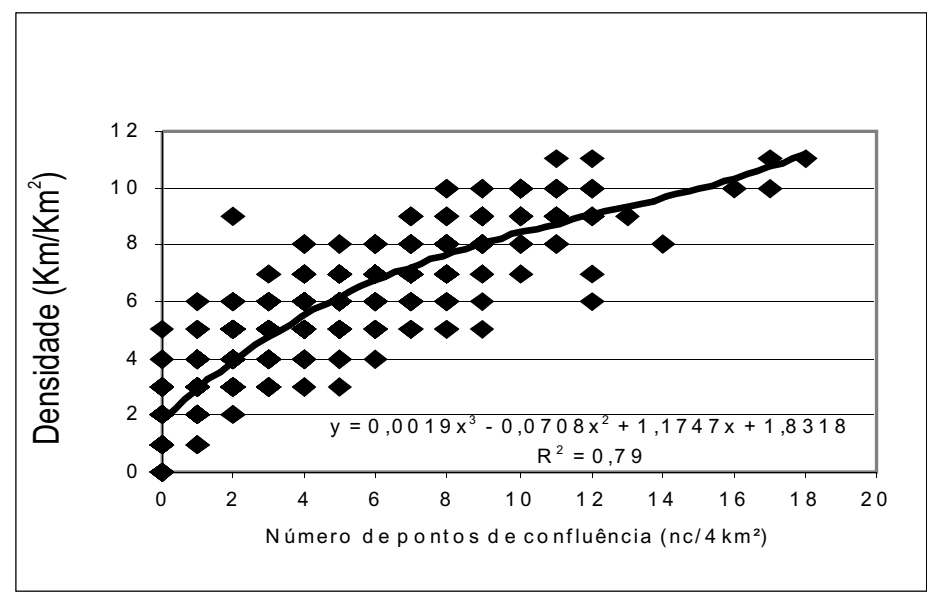

Figura 4. Correlação entre densidades de drenagem determinadas por número de confluências e por comprimento de drenagem na sub-bacia do Santo Anastácio. 
$\mathrm{km} / \mathrm{km}^{2}$.

4.3. Tipos de relevo e densidade de drenagem da sub-bacia do Peixe

O mapeamento realizado pelo IPT $\mathrm{s}$
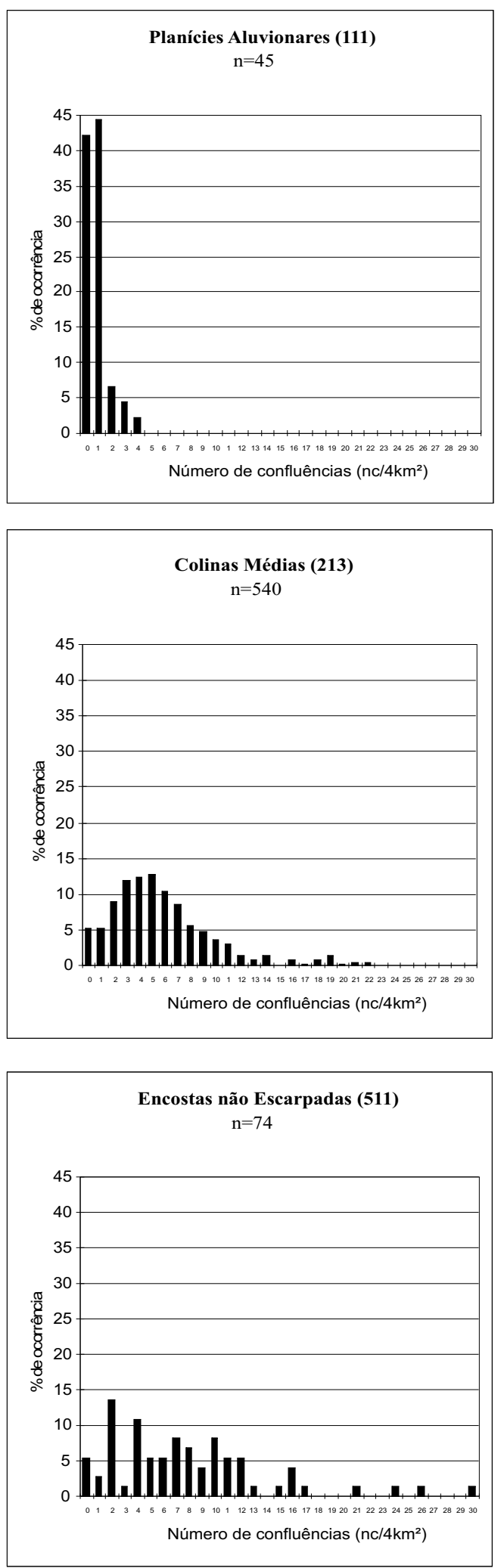

(1981b) determinou 6 tipos de relevo, que foram cartograficamente correlacionados à densidade de drenagem, determinada pelo procedimento do número de confluências. Com os conjuntos de valores de densidade de drenagem obtidos para cada tipo de relevo, foram elaborados os
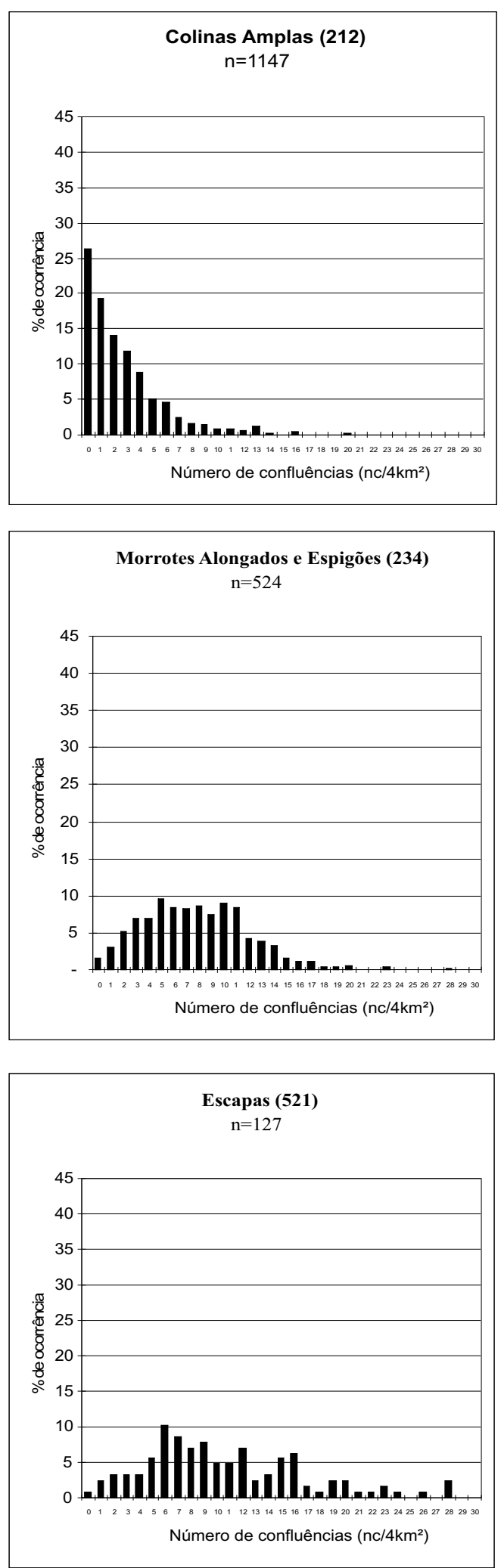

Figura 5. Correlação entre densidade de drenagem e tipos de relevo segundo IPT (1981b). 
Verifica-se nesses histogramas distribuições melhor definidas para os tipos de relevo de menor energia. Os conjuntos que definem as encostas não escarpadas e as escarpas são os que apresentam maiores dispersões de valores de densidade de drenagem, provavelmente porque constituam, conforme legenda do mapa geomorfológico do IPT (1981b), relevos de transição.

Somando-se, para cada tipo de relevo, as porcentagens dos índices $\mathrm{nc} / \mathrm{km} 2$ até atingir $50 \%$ ou mais, foram estabelecidos os índices que melhor caracterizam tais tipos de relevo, conforme a Tabela 3. Observa-se nessa tabela o que já se tinha constatado nos histogramas, ou seja, o aumento da dispersão dos índices com o aumento da energia do relevo. Verifica-se também uma boa correlação dos resultados obtidos com a descrição qualitativa da densidade de drenagem de cada tipo de relevo, elaborada pelo IPT (1981b).

Tabela 3. Tipos de relevo e densidades de drenagem da sub-bacia do rio do Peixe

\begin{tabular}{|c|c|c|}
\hline $\begin{array}{l}\text { Tipo de Relevo } \\
\text { IPT (1981b) }\end{array}$ & $\begin{array}{l}\text { Densidade de Drenagem } \\
\text { Descrição IPT (1981b) }\end{array}$ & $\begin{array}{c}\text { Índices mais freqüentes de } \\
\text { Densidade de Drenagem }\left(\mathrm{nc} / 4 \mathrm{~km}^{2}\right)\end{array}$ \\
\hline Planícies Aluvionares & Baixa & 0 a 1 \\
\hline Colinas Amplas & Baixa & 0 a 2 \\
\hline Colinas Médias & Média a baixa & 2 a 6 \\
\hline Morrotes Alongados & Média a alta & 5 a 11 \\
\hline Encostas não Escarpadas & Média & 0 a 12 \\
\hline Escarpas & Alta & 5 a 16 \\
\hline
\end{tabular}

Com base nesses índices foram estabelecidas as classes de declividade para a aplicação dos tons de cinza de cada quadrícula no sentido de se obter o mapa da distribuição espacial das densidades de drenagem da subbacia do Peixe, apresentado na Figura 6, juntamente com os tipos de relevo considerados.

O mapa da Figura 6 destaca com grande evidência a existência de dois compartimentos geomorfológicos, marcados por índices elevados de densidade de drenagem, nas cabeceiras e a jusante, separados por um compartimento com índices menores. O compartimento de jusante é marcado pela presença de morrotes alongados, espigões e colinas médias, enquanto o das cabeceiras apresenta uma maior diversidade de tipos de relevo, incluindo, além destes, escarpas e encostas não escarpadas. Os índices menores refletem a presença das colinas amplas, que também ocorrem na área extrema de jusante com os relevos aluviais.

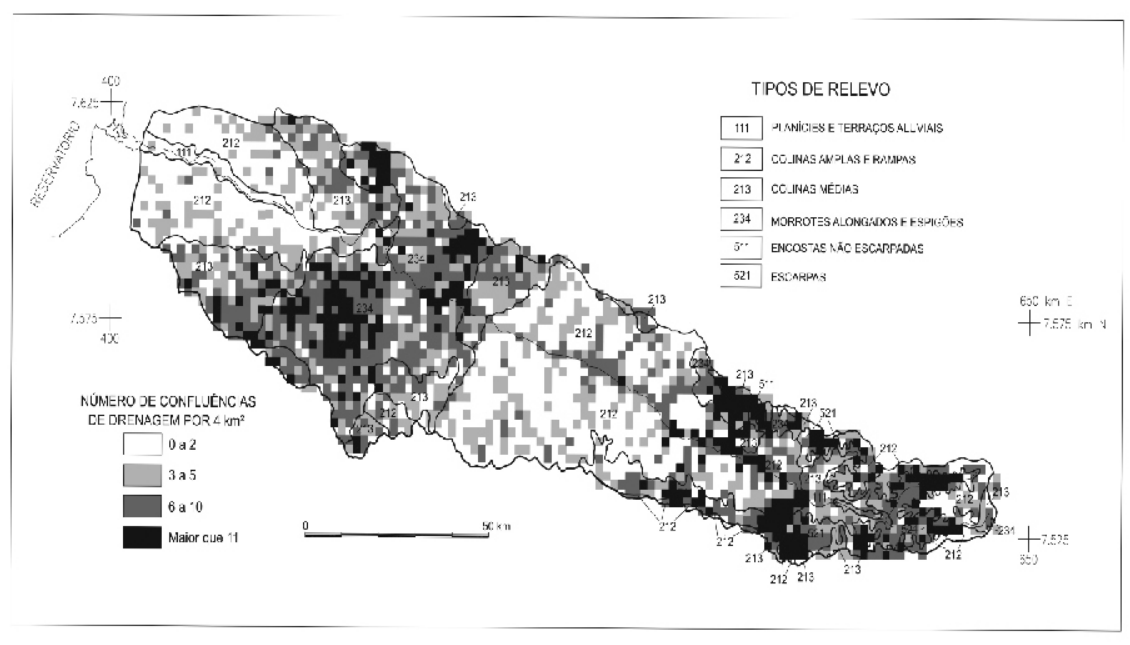

Figura 6. Distribuição da densidade de drenagem na sub-bacia do Peixe e tipos de relevo, segundo IPT (1981b) 
Verifica-se nesses histogramas distribuições melhor definidas para os tipos de relevo de menor energia. Os conjuntos que definem as encostas não escarpadas e as escarpas são os que apresentam maiores dispersões de valores de densidade de drenagem, provavelmente porque constituam, conforme legenda do mapa geomorfológico do IPT (1981b), relevos de transição.
Somando-se, para cada tipo de relevo, as porcentagens dos índices $\mathrm{nc} / \mathrm{km} 2$ até atingir $50 \%$ ou mais, foram estabelecidos os índices que melhor caracterizam tais tipos de relevo, conforme a Tabela 3. Observa-se nessa tabela o que já se tinha constatado nos histogramas, ou seja, o aumento da dispersão dos índices com o aumento da energia do relevo. Verifica-se também uma boa correlação dos resultados obtidos com a descrição qualitativa da densidade

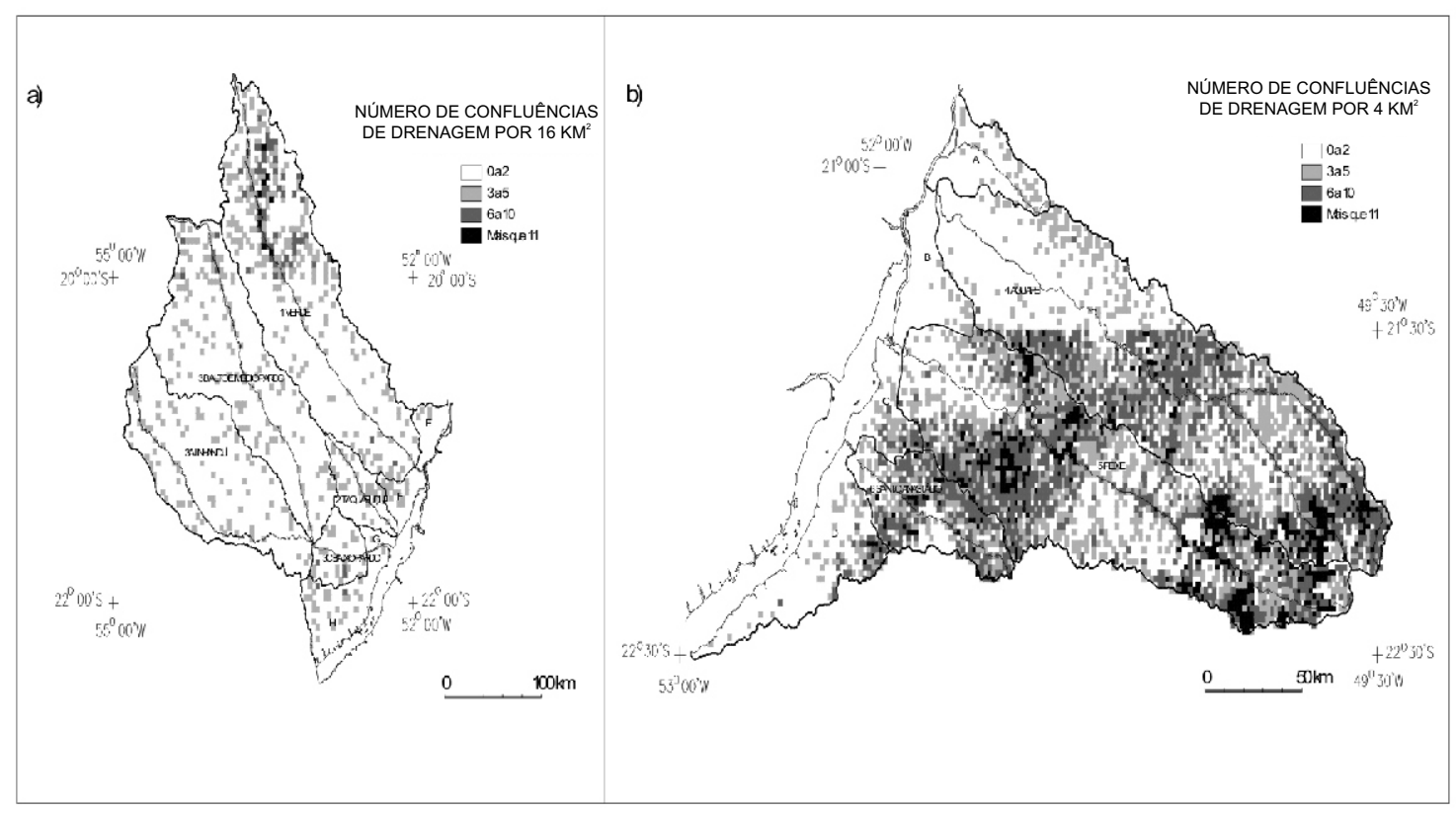

Figura 7. Densidade de drenagem da bacia incremental de Porto Primavera. a) Lado MS; b) Lado SP

de drenagem de cada tipo de relevo, elaborada pelo IPT (1981b).

Com base nesses índices foram estabelecidas as classes de declividade para a aplicação dos tons de cinza de cada quadrícula no sentido de se obter o mapa da distribuição espacial das densidades de drenagem da sub-bacia do Peixe, apresentado na Figura 6, juntamente com os tipos de relevo considerados.

O mapa da Figura 6 destaca com grande evidência a existência de dois compartimentos geomorfológicos, marcados por índices elevados de densidade de drenagem, nas cabeceiras e a jusante, separados por um compartimento com índices menores. O compartimento de jusante é marcado pela presença de morrotes alongados, espigões e colinas médias, enquanto o das cabeceiras apresenta uma maior diversidade de tipos de relevo, incluindo, além destes, escarpas e encostas não escarpadas. Os índices menores refletem a presença das colinas amplas, que também ocorrem na área extrema de jusante com os relevos aluviais.

\subsection{Mapas de densidade de drenagem da bacia}

\section{incremental de Porto Primavera}

A Figura 7 apresenta os mapas de densidade de drenagem da bacia incremental de Porto Primavera. A comparação entre os lados SP e MS destaca as áreas de maior densidade de drenagem em SP, conforme já observado na análise das cartas 1:250.000.

No lado SP é flagrante a diferença de distribuição de densidades de drenagem a sul e a norte da latitude que separa diferentes autores das cartas topográficas 1:50.000, conforme articulação de cartas apresentada na Figura 3. Ao norte desta latitude, os índices menores indicam que o critério de mapeamento de linhas de drenagem adotado pelo IGG/SP (1967) não considerou linhas de drenagem que foram consideradas pelo IBGE (1973-1975).

\section{Conclusões}

As conclusões que podem ser formuladas, a partir da análise realizada, dizem respeito aos procedimentos adotados; à correlação 
à caracterização da bacia incremental do reservatório de Porto Primavera, inclusive a correlação da densidade de drenagem com o potencial de produção de sedimentos das subbacias monitoradas, como a seguir.

\section{Dos procedimentos}

Quanto aos procedimentos, evidenciouse que a densidade de drenagem, medida em cartas topográficas, constitui um índice que depende não só da escala das cartas como também dos autores dos procedimentos cartográficos, pois critérios diferentes de mapeamento da rede de drenagem resultam em diferentes valores de densidade.

A adoção do procedimento de contagem do número de confluências por quilômetro quadrado $\left(\mathrm{nc} / \mathrm{km}^{2}\right)$, quando cartas digitalizadas não são disponíveis, é aceitável para efeito comparativo de diferentes sub-bacias. Neste caso é recomendável que seja realizado ensaio de correlação entre este índice e o índice definido pelo comprimento em quilômetros por quilômetro quadrado $\left(\mathrm{km} / \mathrm{km}^{2}\right)$, sendo a regressão polinomial aquela que melhor correlação oferece, conforme já apontado por Almeida \& Romariz (1988).

A definição de classes de densidade de drenagem tem seu melhor suporte na correlação com tipos de relevo, quando mapas geomorfológicos forem disponíveis, conforme exposto a seguir.

\section{Da correlação com tipos de relevo}

A correlação dos índices mais freqüentes de densidade de drenagem com os tipos de relevo mapeados por IPT (1981a) na sub-bacia do rio do Peixe, possibilitou a definição de classes com as quais foi realizado o mapeamento da densidade de drenagem em

Tabela 4. Produção específica de sedimentos das sub-bacias monitoradas (Carvalho et al., 2004) e índices de densidade de drenagem

\begin{tabular}{ccccc}
\hline & Sub-bacia & $\begin{array}{c}\text { Área } \\
\left(\mathrm{km}^{2}\right)\end{array}$ & $\begin{array}{c}\text { Densidade de drenagem } \\
\left(\mathrm{km} / \mathrm{km}^{2}\right)\end{array}$ & $\begin{array}{c}\text { Produção específica de } \\
\text { sedimentos }\left(\mathrm{t} / \mathrm{km}^{2} / \mathrm{ano}\right)\end{array}$ \\
\hline \multirow{2}{*}{ MS } & Verde & 22.325 & 0,229 & 19,5 \\
& Pardo & 32.889 & 0,254 & 34,0 \\
\hline \multirow{2}{*}{ SP } & Aguapeí & 12.055 & 0,431 & 134,0 \\
& Peixe & 9.979 & 0,435 & 192,0 \\
\hline
\end{tabular}

cartas 1:50.000, em quadrículas de 2 × $2 \mathrm{~km}$.

O mapa assim obtido permite detalhar os compartimentos dos tipos de relevo podendo subsidiar o planejamento de medidas tais como instalação de postos de medidas sedimentométricas e priorização de áreas para ações preventivas de controle de produção de sedimentos, considerando-se a densidade de drenagem como um parâmetro indicador privilegiado do potencial de produção de sedimentos das bacias, conforme proposto a seguir.

Da bacia incremental do reservatório de Porto Primavera: perspectiva da densidade de drenagem como indicador de produção de sedimentos

No estudo sobre o assoreamento do reservatório de Porto Primavera, realizado por Carvalho et al. (2004), foi determinada a produção específica de sedimentos das subbacias monitoradas com postos sedimentométricos, possibilitando uma comparação com os índices de densidade de drenagem, conforme a Tabela 4.
Embora a produção de sedimentos dependa de um grande número de fatores, a comparação realizada nessa Tabela 4 mostra tendências semelhantes dos valores de densidade de drenagem em comparação com a produção específica nas 4 sub-bacias monitoradas. Provavelmente, isso seja devido ao fato da densidade de drenagem não só apresentar uma relação direta com o potencial de transferência de sedimentos (quanto maior a densidade de drenagem, maior o potencial de transferência), mas também refletir os outros fatores que condicionam o potencial de geração das partículas sedimentares ou erosão propriamente dita, ou seja, clima, relevo, solos, etc., enfim, os mesmos que condicionam o estabelecimento da rede drenagem nas bacias hidrográficas.

Pode-se considerar a perspectiva de que a densidade de drenagem, atuante nas duas principais fases de produção de sedimentos de uma bacia, ou seja, de forma indireta na erosão e direta na transferência, seja considerada como indicador privilegiado do potencial de produção de sedimentos das bacias.

$\mathrm{Na}$ análise realizada, o mapeamento da bacia incremental do reservatório de Porto 
à caracterização da bacia incremental do reservatório de Porto Primavera, inclusive a correlação da densidade de drenagem com o potencial de produção de sedimentos das subbacias monitoradas, como a seguir.

\section{Dos procedimentos}

Quanto aos procedimentos, evidenciouse que a densidade de drenagem, medida em cartas topográficas, constitui um índice que depende não só da escala das cartas como também dos autores dos procedimentos cartográficos, pois critérios diferentes de mapeamento da rede de drenagem resultam em diferentes valores de densidade.

A adoção do procedimento de contagem do número de confluências por quilômetro quadrado $\left(\mathrm{nc} / \mathrm{km}^{2}\right)$, quando cartas digitalizadas não são disponíveis, é aceitável para efeito comparativo de diferentes sub-bacias. Neste caso é recomendável que seja realizado ensaio de correlação entre este índice e o índice definido pelo comprimento em quilômetros por quilômetro quadrado $\left(\mathrm{km} / \mathrm{km}^{2}\right)$, sendo a regressão polinomial aquela que melhor correlação oferece, conforme já apontado por Almeida \& Romariz (1988).

A definição de classes de densidade de drenagem tem seu melhor suporte na correlação com tipos de relevo, quando mapas geomorfológicos forem disponíveis, conforme exposto a seguir.

\section{Da correlação com tipos de relevo}

A correlação dos índices mais freqüentes de densidade de drenagem com os tipos de relevo mapeados por IPT (1981a) na sub-bacia do rio do Peixe, possibilitou a definição de classes com as quais foi realizado o mapeamento da densidade de drenagem em cartas 1:50.000, em quadrículas de 2 $\mathrm{x} 2 \mathrm{~km}$.

O mapa assim obtido permite detalhar os compartimentos dos tipos de relevo podendo subsidiar o planejamento de medidas tais como instalação de postos de medidas sedimentométricas e priorização de áreas para ações preventivas de controle de produção de sedimentos, considerando-se a densidade de drenagem como um parâmetro indicador privilegiado do potencial de produção de sedimentos das bacias, conforme proposto a seguir.

\section{Da bacia incremental do reservatório de Porto Primavera: perspectiva da densidade de drenagem como indicador de produção de sedimentos}

No estudo sobre o assoreamento do reservatório de Porto Primavera, realizado por Carvalho et al. (2004), foi determinada a produção específica de sedimentos das sub-bacias monitoradas com postos sedimentométricos, possibilitando uma comparação com os índices de densidade de drenagem, conforme a Tabela 4. Embora a produção de sedimentos dependa de um grande número de fatores, a comparação realizada nessa Tabela 4 mostra tendências semelhantes dos valores de densidade de drenagem em comparação com a produção específica nas 4 sub-bacias monitoradas. Provavelmente, isso seja devido ao fato da densidade de drenagem não só apresentar uma relação direta com o potencial de transferência de sedimentos (quanto maior a densidade de drenagem, maior o potencial de transferência), mas também refletir os outros fatores que condicionam o potencial de geração das partículas sedimentares ou erosão propriamente dita, ou seja, clima, relevo, solos, etc., enfim, os mesmos que condicionam o estabelecimento da rede drenagem nas bacias hidrográficas.

Pode-se considerar a perspectiva de que a densidade de drenagem, atuante nas duas principais fases de produção de sedimentos de uma bacia, ou seja, de forma indireta na erosão e direta na transferência, seja considerada como indicador privilegiado do potencial de produção de sedimentos das bacias.

$\mathrm{Na}$ análise realizada, o mapeamento da bacia incremental do reservatório de Porto Primavera, evidencia uma assimetria notável de índices de densidade de drenagem entre os lados de SP e MS, indicando que as sub-bacias do lado de SP apresentam condições potenciais de uma maior produção específica de sedimentos para o reservatório. Esta indicação é confirmada pelas taxas de produção de sedimentos, que segundo a mesma Tabela 4, são da ordem das dezenas no lado MS e das centenas no lado SP.

Novas pesquisas são desejáveis para se confirmar a eficiência da densidade de drenagem como indicador do potencial de produção de sedimentos de bacias hidrográficas. Neste sentido, deverão ser considerados os resultados hidrossedimentométricos que estão sendo coletados nas duas novas estações instaladas nas sub-bacias do Taquaruçu e Santo Anastácio, decorrentes dos estudos realizados (Carvalho et al., 2004), completando o monitoramento das 6 principais sub-bacias da bacia incremental de Porto Primavera. Assim, daqui a alguns anos, séries de medidas consistentes, que estão sendo realizadas pela Cesp, possibilitarão novas correlações da densidade de drenagem com a produção de sedimentos das sub-bacias da bacia incremental do reservatório de Porto Primavera.

\section{Referências Bibliográficas}

Abrahans, A.D. 1972. Drainage densities and sediment yield in Eastern Australia. Australian Geographical Studies, 10(1): 19-41. (in Christofoletti, 1979). Almeida, C. \& Romariz, C. 1988. Aspectos 
Almeida, C. \& Romariz, C. 1988. Aspectos quantitativos da drenagem superficial no Algarve (Portugal). Geolis - vol.II (2): 110114.

Autodesk, 2004. AutoCAD. www.autodesk.com.

Bertoni, J. \& Lombardi Neto, F. 1985. Conservação do solo. Piracicaba: Livroceres, 392 p.

Calvo-Alvarado, J.C. \& Gregory, J.D. 1997. Predicting Mean Annual Runoff and Suspended Sediment Yield in Rural Watersheds in North Carolina. http://www2.ncsu.edu/ncsu/CIL/WRRI

Carvalho, N.O.; Alves, C.F.C.; Oliveira, A.M.S.; Buratto; R.B.; Perrella, M.C.V.; Celeri, A.; Tanaka, R.; Ferreira, A.S. 2004. Sedimentological Studies of the Porto Primavera Reservoir, Parana River, Brazil. International Symposium on River Sedimentation, 9. Ychang. Paper submitted. Oct. 2004.

Chakraborti, 1991. Sediment yield prediction and prioritization of watershed using Remote $\mathrm{S}$ e $\mathrm{n} \mathrm{s}$ i n g d a t a . http://www.gisdevelopment.net/aars/acrs/19 91/psq/ps003a.shtml

Christofoletti, A. 1979. A análise da densidade de drenagem e suas implicações geomorfológicas. Geografia, 4(8): 23-42: 23-42.

Christofoletti, A. 1980. Geomorfologia. São Paulo: Ed. Edgard Blucher Ltda. 188p.

Christofoletti, A. 1983. A significância da densidade de drenagem para a análise geomorfológica. Bol. Geogr. Teorética, Rio Claro, 13 (26): 27 53.

Demattê, J.A.M. 1992. Utilização de parâmetros de drenagem com o auxílio de fotografias aéreas na caracterização de solos desenvolvidos de rochas eruptivas no estado do Paraná. Dissertação de mestrado. Piracicaba: ESALQ.

Foster, G.R. 1987. Water Erosion Prediction Project, WEPP. W. Lafayette, National Soil Erosion Research Laboratory, USDA Agricultural Research Service. 43 p. (NSERL Report,1)

Golden Software Inc. 2002. Surfer v. 8. www.goldensoftware.com.

Horton, R.E. 1945. Erosional development of streams and their drainage basins: hydrophysical approach to quantitative morphology. Geological Society of America Bulletin. 56 (3): 275-370. (in Christofoletti, 1983).

IPT. 1981a. (Instituto de Pesquisas Tecnológicas do Estado de São Paulo). Mapa geomorfológico do Estado de São Paulo. Escala 1:1.000.000. São Paulo: IPT.2v. (IPT, Monografia 5).

IPT. 1981b (Instituto de Pesquisas Tecnológicas do Estado de São Paulo). Mapa geológico do Estado de São Paulo. Escala 1:500.000. São Paulo: IPT.2v. (IPT, Monografia 6).

Neumann, L. 1900. Die Dichte des Flussnetzes in Schwarzwalde. Beitrage fur Geophysiche. (I
(In Christofoletti, 1983).

Rodrigues, S.F.J. 2003. Avaliação das alterações da rede de drenagem em sub-bacias e microbacias do alto e baixo rio Capivari (Louveira e Rafard/SP). Dissertação de mestrado. São Carlos: EESC/USP.

Seplan/MS \& IBGE DRN/GO. 1987. (Secretaria de Estado de Planejamento e das Ciências e Tecnologia. Instituto Brasileiro de Geografia e Estatística). Projeto de Estudos Integrados e Potencial dos Recursos Naturais. Mapa - Geomorfologia 1:1.000.000 e 1:250.000. Campo Grande: Coordenadoria de Recursos Naturais.

Silva, L.C.F. 1993. Fotointerpretação de redes de drenagem e caracterização do relevo e dos solos do município de São Pedro/SP. Tese de doutoramento. Piracicaba: Esalq.

Themag/Engea/Umah. 1994. Estudo de impacto ambiental. Relatório de impacto no meio ambiente da Usina Hidroelétrica de Porto Primavera. São Paulo: Cesp.

WALM, 2003. Caracterização e qualificação dos processos hidrossedimentológicos no reservatório da UHE Eng. Sergio Motta. Relatórios Técnicos. Walm Engenharia e Tecnologia Ambiental. São Paulo: CESP. CD ROM.

Williams, J.R. 1975. Sediment yield prediction with universal equation using runoff energy factor. In: Sediment Yield Workshop, Oxford, 1972. Proceedings... Oxford, USDA, Sedimentation Laboratory: .244252 (USDA. Publication ARS-S-40) 